\title{
Development of an Epitope-Based Competitive ELISA for the Detection of Antibodies against Tibetan Peste des Petits Ruminants Virus
}

\author{
Guo-Rui Zhang a, b Rui-Song Yu ${ }^{a} \quad$ Jiang-Yong Zeng ${ }^{c} \quad$ Yu-Min Zhu ${ }^{a}$ \\ Shi-Juan Dong ${ }^{\mathrm{a}}$ Luobu Dunzhu ${ }^{\mathrm{d}}$ Se Zhu ${ }^{\mathrm{c}}$ Ciren Duoji ${ }^{\mathrm{c}}$ Zhi-Hai Lei ${ }^{\mathrm{b}}$ Zhen Li $^{\mathrm{a}}$ \\ ${ }^{a}$ Institute of Animal Sciences and Veterinary Medicine and Shanghai Key Laboratory of Agricultural Genetics and \\ Breeding, Shanghai Academy of Agricultural Sciences (SAAS), Shanghai, and ${ }^{b}$ College of Veterinary Medicine, \\ Nanjing Agricultural University, Nanjing, China, ${ }^{C}$ Tibet Livestock Research Institute, Tibet Academy of Agricultural \\ and Animal Sciences, Lhasa, and ${ }^{\mathrm{d} C o l l e g e}$ of Agriculture and Animal Husbandry, Tibet University, Linzhi, \\ Tibet, China
}

\section{Key Words}

Competitive ELISA - Peste des petits ruminants virus •

$\mathrm{N}$ gene $\cdot$ Epitope $\cdot$ Antibody

\begin{abstract}
Aims: To develop an effective diagnostic kit, based on a competitive ELISA-based system (cELISA), for detecting serum antibody against peste des petits ruminants virus (PPRV). Methods: Epitope peptides of the nucleocapsid (N) protein of Tibetan PPRV were synthesized chemically and injected into rabbits to prepare hyperimmune antisera. Test sera were incubated simultaneously with hyperimmune antisera and added to the wells of ELISA plates coated previously with recombinant $\mathrm{N}$ protein. Horseradish peroxidaseconjugated goat anti-rabbit antibody was employed to detect the quantity of hyperimmune antisera combined with recombinant N protein. Results: A cELISA has been developed for monitoring PPRV infections with a cutoff value of 35 . Relative sensitivity and specificity values of the epitopebased cELISA were 96.18 and $91.29 \%$, respectively, when compared with a commercial cELISA kit in a test involving 1,039 serum samples. Conclusion: We report an efficient method for preparing antibody suitable for incorporation into a cELISA that can be used routinely for the detection of
\end{abstract}

PPRV antibodies in serum samples. The method eliminated the requirement for virus culture and monoclonal antibody preparation, reduced the biorisk posed by virus-dependent manipulations, and the performance of the resultant cELISA compared favorably with a commercially available cELISA kit.

Copyright $\odot 2012$ S. Karger AG, Basel

Peste des petits ruminants (PPR) is an acute, highly contagious and economically important viral disease with morbidity and mortality rates as high as 100 and $90 \%$, respectively [1]. PPR, a contagion of goats and sheep, is characterized by severe pyrexia, oculonasal discharges, necrotizing and erosive stomatitis, enteritis and pneumonia. Initially epidemic in Ivory Coast and West Africa [2], the disease later spread across sub-Saharan Africa, the Arabian Peninsula and Southwest Asia [3]. In July 2007, an outbreak of PPR in the southwestern Ngari region of Tibet resulted in heavy mortality among the goat population and huge economic losses to local farmers [4].

\section{G.-R. Zhang and R.-S. Yu contributed equally to this work.}

\section{KARGER}

Fax +4161306 1234

E-Mail karger@karger.ch

www.karger.com (c) 2012 S. Karger AG, Basel

$0300-5526 / 13 / 0561-0055 \$ 38.00 / 0$

Accessible online at:

www.karger.com/int
Dr. Zhen Li

Institute of Animal Sciences and Veterinary Medicine and

Shanghai Key Laboratory of Agricultural Genetics and Breeding

Shanghai Academy of Agricultural Sciences (SAAS), Shanghai (China)

Tel. +86216220 0389, E-Mail zhenli60@163.com 
The causative agent, peste des petits ruminants virus (PPRV), is an enveloped RNA virus belonging to the genus Morbillivirus of the family Paramyxoviridae that has a single-stranded, negative-sense RNA genome encoding eight proteins in the order $3^{\prime}-\mathrm{N}-\mathrm{P} / \mathrm{C} / \mathrm{V}-\mathrm{M}-\mathrm{F}-\mathrm{H}-\mathrm{L}-5^{\prime}$. PPRV is most closely related antigenically to rinderpest virus (RPV) [5], another member of the genus Morbillivirus, which can infect all artiodactyl species, with cattle and buffalo being the most susceptible [6]. Laboratory confirmation of PPRV infection is normally carried out using an enzyme-linked immunosorbent assay (ELISA) but diagnosis of PPR is often ambiguous in areas where the disease coexists with RPV. Various ELISA protocols, employing monoclonal antibody raised either against hemagglutinin protein $[7,8]$ or nucleoprotein [9], have been developed. At present, two ELISA kits are available commercially $[7,9,10]$, both of which employ monoclonal antibodies developed using African lineages of PPRVs or their expressed antigens.

In the initial period of a PPRV epidemic, quarantine measures to isolate infected animals are essential to control the rapid spread of the disease. For this reason, effective diagnostic kits for antigen or antibody detection are required by countries and regions threatened by PPRV epidemics. In order to address this need, we set out to develop a competitive ELISA-based system (cELISA) for detecting serum antibody against PPRV in which the coating antigen was artificially synthesized PPRV nucleocapsid $(\mathrm{N})$ protein and the competitive polyclonal serum was obtained by immunizing animals with synthetic peptides that included specific PPRV epitopes. Such peptides have been used to detect serum antibodies because they are cheaper to produce than the entire protein $[11,12]$, exhibit good immunogenicity and can be employed to produce hyperimmune antiserum for ELISAs. Theoretically, the method should be capable of differentiating between PPR and rinderpest.

Recombinant N protein of Tibetan PPRV employed as capture antigen was prepared as described previously [13]. Four peptides of the $\mathrm{N}$ protein were synthesized by GL Biochem (Shanghai) Ltd and designated as follows: TPA (132-145) STEGPSSGGKKRIN, TPB (433-443) ATREGVKAAIP, TPC (467-473) LLPEIMP, and TPD (455-473) RPGRPRGETPGQLLLEIMP. Peptide sequences were selected according to Dechamma et al. [14].

For the screening of peptides before immunizing rabbits, wells of ELISA plates (Maxisorp F96; Nunc, Kamstrup, Denmark) were coated with the synthetic peptides in carbonate-bicarbonate buffer overnight at $4^{\circ}$ and blocked with $100 \mu \mathrm{l}$ of $5 \%$ skimmed milk powder in phos- phate-buffered saline (PBS) for $2 \mathrm{~h}$ at $37^{\circ}$. After washing with PBS Tween 20, goat anti-PPRV and goat anti-RPV sera were added to duplicate wells and incubated for $1 \mathrm{~h}$ at $37^{\circ}$. After washing as before, rabbit anti-goat IgG (Immunology Consultants Laboratory, Newberg, Oreg., USA), diluted 1:8,000 and conjugated with horseradish peroxidase (Santa Cruz Biotechnology, Santa Cruz, Calif., USA), was added followed by incubation for $1 \mathrm{~h}$ at $37^{\circ}$. Antigen-antibody reactions were detected using 3, $3^{\prime}, 5,5^{\prime}$ tetramethylbenzidine and measured spectrophotometrically at $450 \mathrm{~nm}$.

Previously confirmed PPRV-negative serum samples $(n=488)$ were employed to determine the cutoff value of the epitope-based cELISA, and 1,039 serum samples were used to assess the validity of the epitope-based cELISA compared with a commercial cELISA kit (Cirad Bios, UPR15, TA A-15/G Campus International Baillarguet, Montpellier, France). A total of 770 recently collected serum samples of well-defined origin and history were evaluated using the newly established cELISA to determine the immunization state of animals raised in a PPRVinfected area of Tibet.

Peptide antiserum was obtained by intramuscular injection of female New Zealand white rabbits $(\sim 1 \mathrm{~kg}$ body weight) at four multiple sites with $75 \mathrm{mg}$ of TPD dissolved in $500 \mu \mathrm{l}$ of PBS mixed with an equal volume of Freund's complete adjuvant (Sigma-Aldrich, San Francisco, Calif., USA). Animals were given booster doses of the same antigen mixed with Freund's incomplete adjuvant (SigmaAldrich) 28, 40 and 60 days after the first injection. Hyperimmune serum (peptide antiserum) was dialyzed against $0.15 \mathrm{M}$ PBS for $48 \mathrm{~h}$ at $4^{\circ}$, changing the buffer every $12 \mathrm{~h}$, sterilized by filtration and stored at $-20^{\circ}$.

Peptide antiserum titers were measured by indirect ELISA accomplished as follows: wells of ELISA plates were coated with recombinant $\mathrm{N}$ protein in carbonatebicarbonate buffer overnight at $4^{\circ}$ and then blocked with $100 \mu \mathrm{l}$ of $5 \%$ skimmed milk powder in PBS for $2 \mathrm{~h}$ at $37^{\circ}$. After washing with PBS Tween 20 , rabbit sera $(0,7,18,35$, 55,65 and $90 \mathrm{dpi}$ ) were added to duplicate wells and incubated for $1 \mathrm{~h}$ at $37^{\circ}$. After washing as before, goat antirabbit IgG diluted 1:8,000 and conjugated with horseradish peroxidase (Abgent, San Diego, Calif., USA) was added, followed by incubation for $1 \mathrm{~h}$ at $37^{\circ}$. Antigen-antibody reactions were detected using 3,3',5,5'-tetramethylbenzidine and measured at $450 \mathrm{~nm}$.

Conditions used for the competitive ELISA were based on the method described for detecting RPV-specific antibody [15]. Microtiter ELISA plates were coated with 100 $\mu \mathrm{l}$ recombinant $\mathrm{N}$ protein $(320 \mathrm{ng} / \mathrm{ml})$ for $1 \mathrm{~h}$ at $37^{\circ}$ with 


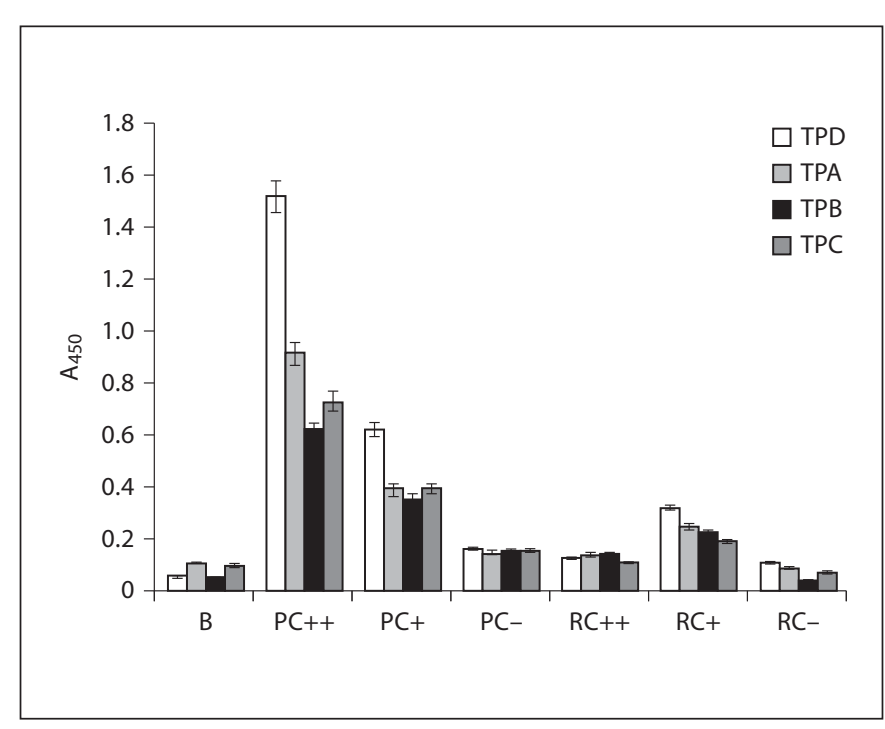

Fig. 1. Comparison of the binding capacity of PPRV and RPV antisera for four synthetic peptides derived from the $\mathrm{N}$ protein of PPRV. B = Blank; $\mathrm{PC}++=$ strong positive PPRV antiserum; $\mathrm{PC}+=$ weak positive PPRV antiserum; $\mathrm{PC}-=$ PPRV-negative serum; $\mathrm{RC}++$ = strong positive $\mathrm{RPV}$ antiserum; $\mathrm{RC}+$ = weak positive RPV antiserum; RC- = RPV-negative serum.

constant agitation. After adsorption of the antigen, test sera at a final dilution of 1:20 were incubated simultaneously with rabbit hyperimmune serum (final dilution $1: 1,000$ ) in blocking buffer (supplemented with $0.5 \%$ lamb serum). Wells without test and hyperimmune serum served as the conjugate control (100\% competition), and wells without test serum served as the hyperimmune serum control ( $0 \%$ competition). Serum controls included wells with a strong positive, a weak positive or a negative serum to ensure that similar levels of inhibition were obtained between tests. Absorbance values were converted to percentage inhibition (PI) values using the following formula:

$$
\mathrm{PI}=100-\left(\mathrm{A}_{450} \text { test } / \mathrm{A}_{450} 0 \% \text { control }\right) \times 100
$$

where ' $\mathrm{A}_{450}$ test' denotes absorbance values of wells containing test sera and ' $\mathrm{A}_{450} 0 \%$ control' denotes absorbance values of wells containing hyperimmune serum without test serum.

The antigen concentration that gave $75 \%$ of the $\mathrm{A}_{450}$ plateau in the indirect ELISA was employed as the optimum coating concentration, and the optimum antibody concentration was determined using the checkerboard titration test $[16,17]$. To determine the optimum antigen/ antibody binding time, the standard deviation (SD) values of three tests (in which the reactants were allowed to

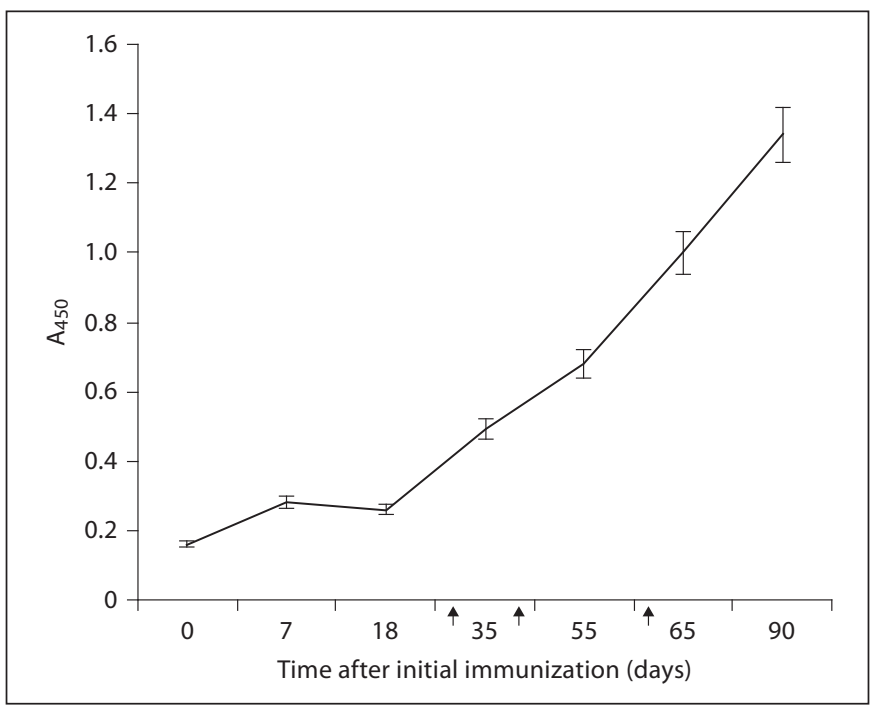

Fig. 2. Dynamics of postimmunization antibody production. The three black arrows below the $\mathrm{x}$-axis indicate the times $(28,40$ and 60 days after the first immunization) when the animals were given booster doses of antigen. Error bars indicate the SD values for five determinations. bind for 15, 30 and $60 \mathrm{~min}$, respectively) using eight different serum samples were compared (each measurement was carried out 4 times), and the value with the smallest SD was adopted as optimal.

The mean PI value obtained for 488 negative serum samples plus twice the SD value was adopted as the cutoff value for the cELISA. Reproducibility of the assay was determined using 20 serum samples. For each sample, the coefficient of variation (CV) was calculated between plates using four different plates on different occasions (interassay variation) and four replicates within the same plate (intra-assay variation).

Each of the four peptides bound to PPRV antiserum, with the strongest affinity observed with TPD, whereas only relatively very weak binding was recorded between the epitopes and RPV antiserum (fig. 1). The difference in the binding affinity of TPD for PPRV and RPV antisera was sufficiently significant $(\mathrm{p}<0.01)$ to suggest employing the epitope for the differential diagnosis of PPRV and RPV infections. Indirect ELISA revealed that the level of reactivity between hyperimmune sera and $\mathrm{N}$ protein increased following booster immunizations (fig. 2).

An $\mathrm{A}_{450}$ value of $1.074,75 \%$ of the maximum $\mathrm{A}_{450}$ value of 1.40 achieved with undiluted antigen, was obtained with $320 \mathrm{ng} / \mathrm{ml}$ of the coating antigen. Selecting this con- 
Table 1. Incidence of animals testing positive for PPRV antibodies in counties of the Ali region of Tibet

\begin{tabular}{lllll}
\hline & Rutog & Gegyai & Gerze & Zanda \\
\hline Sample size, $\mathrm{n}$ & 140 & 198 & 186 & 246 \\
PI range & $14-43$ & $22-41$ & $13-42$ & $14-35$ \\
Positive, $\mathrm{n}$ & 22 & 31 & 29 & 9 \\
Positive, \% & 15.7 & 15.7 & 15.6 & 3.7 \\
\hline
\end{tabular}

centration as optimal, the maximum difference between the PI values of positive and negative samples was recorded using 1:1,000 and 1:5 dilutions of rabbit hyperimmune serum and test sera, respectively. SD values for 32 positive serum samples were $12.75,9.38$, and 7.44 when reaction times of 15, 30 and 60 min were employed, respectively, and the latter was selected for future experiments accordingly.

Using the mean PI value (18.07) obtained for 488 negative serum samples (198 goat and 290 sheep) plus twice the SD (8.39), the cutoff value for the cELISA was calculated to be 35. Interassay CVs ranged from 2.1 to $5.9 \%$ (average $2.89 \%$ ), and the intra-assay CV ranged from 1.5 to $4.7 \%$ (average 2.32\%), based on 20 selected serum samples.

Totally, 333 and 706 serum samples were judged to be anti-PPRV positive and negative, respectively, by the commercial cELISA kit. Of the 333 positive samples, 304 were also judged to be positive by the epitope-based cELISA, corresponding to a relative specificity of $91.29 \%$. Of the 706 negative samples, 679 were similarly assessed by the epitope-based cELISA, corresponding to a relative sensitivity of $96.18 \%$.

PPRV antibody titers in serum from naturally infected animals were markedly higher compared with vaccinated animals. PI values of 36.7 (scored positive) were recorded in 20-fold dilutions of serum from naturally infected animals, whereas 10-fold dilutions of 10 (from 12) serum samples taken from vaccinated animals gave PI values below the 35 cutoff level (scored negative).

Of 770 serum samples taken from the Ali region of Tibet (which consists of Rutog, Gegyai, Gerze and Zanda counties), 91 tested positive using the epitope-based cELISA (table 1). A relatively higher proportion of positives were recorded among samples from Rutog, Gegyai and Gerze counties compared with Zanda (table 1). PI values of the Tibetan samples fluctuated around 30 with a maximum of 42 .

In this study, we sought to develop a cELISA for detecting PPRV infections by substituting monoclonal anti- body with hyperimmune serum obtained by immunizing animals with synthetic epitope peptides derived from the PPRV N protein. Another unique feature of this cELISA was the Tibetan PPRV N protein (expressed from a chemically synthesized gene) employed as the coating antigen. We adopted this approach in order to avoid the hazards associated with handling PPRV, a list A animal pathogen that requires a BSL-3 facility.

Among the structural proteins of morbilliviruses, the $\mathrm{N}$ protein is the most immunogenic and has a highly conserved structure [18]. Dechamma et al. [14] identified PPRV-specific antigen epitopes at the 132-145, 433-443 and 454-472 segments of the $\mathrm{N}$ protein, which suggested these segments might be used for the differential diagnosis of PPRV and RPV infections. We have now confirmed that four synthesized epitopes, TPA, TPB, TPC and TPD, induced hyperimmune sera, and that TPD exhibited the highest affinity for PPRV antibody. We have also demonstrated that the hyperimmune serum obtained by immunizing animals with TPD together with Freund's complete adjuvant is suitable for use in a competitive ELISA.

The epitope-based cELISA had a specificity of $96.18 \%$ and a sensitivity of $91.29 \%$ compared to a commercial cELISA kit (Cirad Bios), which is an authorized product and exhibits good agreement with a VNT [10]. The average CVs were less than $3 \%$ in both intra- and interassays using the epitope-based cELISA, indicating a high degree of reproducibility.

Most of the PPRV-positive serum samples examined in this study were collected from the Ali region of Tibet and, with PI values $<42$, were assessed as weak positive, implying that the animals concerned were only weakly immunized. Since the antigen used to prepare the competitive antiserum had only a low affinity for RPV-positive antisera, the method should, theoretically, be able to distinguish between antibodies to PPRV and RPV.

\section{Acknowledgements}

This work was sponsored by the National Natural Science Foundation of China (Grant No. 31140084) and the National High Technology Research and Development Program of China (863 Program) (No. 2011AA10A208), and the Shanghai Pujiang Program. We thank Shi-Biao Yang from the Yunnan Academy of Animal Science and Veterinary Medicine and Zhi-Liang Wang and Xiao-Dong Wu from the Chinese Animal Epidemic Disease Center for assistance and suggestions relating to sample detection and analysis, and Dr. John Buswell from the Institute of Edible Fungi, SAAS, for linguistic revision of the manuscript. 


\section{References}

$>1$ Abu Elzein EM, Hassanien MM, Al-Afaleq AI, Abd Elhadi MA, Housawi FM: Isolation of peste des petits ruminants from goats in Saudi Arabia. Vet Rec 1990;127:309-310.

2 Gargadennec L, Lalanne A: La peste des petits ruminants. Bull Serv Zootechnol Epiz AOF 1942;5:16-21.

-3 Taylor WP: The distribution and epidemiol ogy of peste des petits ruminants. Prev Vet Med 1984;2:157-166.

4 Wang Z, Bao J, Wu X, Liu Y, Li L, Liu C, Suo L, Xie Z, Zhao W, Zhang W, Yang N, Li J, Wang S, Wang J: Peste des petits ruminants virus in Tibet, China. Emerg Infect Dis 2009; 15:299-301.

7 Gibbs EP, Taylor WP, Lawman MJP, Bryant $\mathrm{J}$ : Classification of peste des petits ruminants virus as the fourth member of the genus Morbillivirus. Intervirology 1979;11:268-274.

$\checkmark 6$ Renukaradhya GJ, Suresh KB, Rajasekhar M, Shaila MS: Competitive enzyme-linked immunosorbent assay based on monoclonal antibody and recombinant hemagglutinin for serosurveillance of rinderpest virus. J Clin Microbiol 2003;41:943-947.

7 Anderson J, McKay JA: The detection of antibodies against peste des petits ruminants virus in cattle, sheep and goats and the possible implications to rinderpest control programmes. Epidemiol Infect 1994;112:225231.
$>_{8}$ Saliki JT, Libeau G, House JA, Mebus CA, Dubovi EJ: Monoclonal antibody-based blocking enzyme-linked immunosorbent assay for specific detection and titration of peste-des-petits-ruminants virus antibody in caprine and ovine sera. J Clin Microbiol 1993;31:1075-1082.

$\checkmark 9$ Libeau G, Prehaud C, Lancelot R, Colas F, Guerre L, Bishop DH, Diallo A: Development of a competitive ELISA for detecting antibodies to the peste des petits ruminants virus using a recombinant nucleoprotein. Res Vet Sci 1995;58:50-55.

10 Anderson J, McKay JA, Butcher RN: The use of monoclonal antibodies in competitive ELISA for the detection of antibodies to rinderpest and peste des petits ruminants viruses; in The Seromonitoring of Rinderpest throughout Africa. Proc Final Res Coordination Meet IAEA Rinderpest Control Projects, Côte d'Ivoire, 1990. IAEA-TECDOC-623, pp 43-53.

11 Brattegaard K, Soroh D, Zadi F, Digbeu H, Vetter KM, De Cock KM: Insensitivity of a synthetic peptide-based test (Pepti-LAV 1-2) for the diagnosis of HIV infection in African children. AIDS 1995;9:656-657.

12 Viscidi RP, Hill PM, Li SJ, Cerny EH, Vlahov D, Farzadegan $H$, Halsey N, Kelen GD, Quinn TC: Diagnosis and differentiation of HTLV-I and HTLV-II infection by enzyme immunoassays using synthetic peptides. J Acquir Immune Defic Syndr 1991;4:11901198.
3 Zhang G, Zeng J, Zhu Y, Dong S, Zhu S, Yu R, Duoji C, Lei Z, Li Z: Development of an indirect ELISA with artificially synthesized $\mathrm{N}$ protein of PPR virus. Intervirology 2012; 55:12-20.

14 Dechamma HJ, Dighe V, Kumar CA, Singh RP, Jagadish M, Kumar S: Identification of T-helper and linear B epitope in the hypervariable region of nucleocapsid protein of PPRV and its use in the development of specific antibodies to detect viral antigen. Vet Microbiol 2006;118:201-211.

15 Libeau G, Diallo A, Calvez D, Lefevre PC: A competitive ELISA using anti-N monoclonal antibodies for specific detection of rinderpest antibodies in cattle and small ruminants. Vet Microbiol 1992;31:147-160.

16 Singh RP, Sreenivasa BP, Dhar P, Bandyopadhyay SK: A sandwich-ELISA for the diagnosis of peste des petits ruminants (PPR) infection in small ruminants using anti-nucleocapsid protein monoclonal antibody. Arch Virol 2004;149:2155-2170.

17 Choi KS, Nah JJ, Ko YJ, Kang SY, Jo NI: Rapid competitive enzyme-linked immunosorbent assay for detection of antibodies to peste des petits ruminants virus. Clin Diagn Lab Immunol 2005;12:542-547.

18 Francki RIB, Fauquet CM, Knudson DL, Brown F: Classification and nomenclature of viruses: Fifth Report of the International Committee on Taxonomy of Viruses. Arch Virol 1991;2(suppl):223-233. 